The seasonal variation was more regular, and was greater both in actual figures and in proportion to the amount present, in the case of protein than in the case of fat.

From October to March the average percentages of all the constituents were higher than from April to September. The difference in milk-sugar is much less, both relatively and absolutely, than the differences in protein and fat. The seasonal variation in percentage of ash is very slight, although in proportion to the amount present it is no smaller than the variation in milk-sugar.

The seasonal variations in solids-not-fat are due chiefly to changes in the percentage of protein.

\title{
THE DETERMINATION OF ROSIN IN VARNISHES.
}

By Augtstus H. Gill.

Received October I, Igo6.

THE presence of rosin in a varnish decreases its resisting power to atmospheric agencies, its power of adhesion to surfaces, and its hardness; furthermore, it means the substitution of the valuable copal or kauri by the cheap rosin or "South Carolina Zanzibar."

The procedure followed consists in the elimination of the turpentine by distillation with steam, of the oil by Twitchell's process, thus obtaining the pure gum resins. These were examined at first by the Hübl method, Table I, then by McIlhiney's bromine method, Table II, and finally and most satisfactorily, the saponification, free acid and ester values, Table V, were determined.

Sixty grams of the well-mixed varnish are weighed into a 500 cc. round-bottomed flask, this connected with a condenser and a two-quart can which furnishes steam; the varnish is warmed just above $100^{\circ}$ by a small flame and kept at this point to prevent the condensation of the steam used for distillation. The distillation is continued until about $500 \mathrm{cc}$. of water have passed over, or until there is but a faint odor of turpentine in the last portions of the distillate. It was noticed with a pure rosin varnish that only a small portion of the gum sticks to the flask, while with pure copal varnish the gum coats the inside of the flask almost completely.

The solvent may be separated from the water, dried by anhy- 
drous sodium sulphate, distilled and weighed; if the specific gravity be taken, a fairly good idea of its purity may be obtained.

The residue in the flask is boiled for an hour over a free flame at a reflux condenser with $150 \mathrm{cc}$. of normal alcoholic potash; this latter is made from absolute alcohol and "potash purified by alcohol." Care should be taken to warm the flask very slowly or on a water-bath first, to prevent the usual bumping of alcoholic solutions; the solution is then cooled, separated from the residue and the latter again treated with the potash solution, repeating the process until practically complete saponification takes place. Usually a residue of about I per cent. remains.

The solutions are united in a separatory funnel and neutralized with hydrochloric acid, causing a precipitate of potassium and lead chlorides, the latter coming from the drier used; water and ether are now added, the latter dissolving the fatty acids and gums liberated by the acid. The ethereal solution is run into a flask, the ether distilled off and a small quantity of absolute alcohol added to the contents of the flask; on this being heated the alcohol passes off carrying the water with it, leaving the dry gums and fatty acids. These are dissolved in ro volumes of absolute alcohol, any residue being added to the gums obtained below, from carrying out this process. Dry hydrochloric acid gas is passed into this solution, it being cooled by ice, until it is saturated. Hot water is poured into the flask and its contents boiled over a free flame, care being taken at incipient ebullition to prevent frothing over.

The contents of the flask are cooled and shaken out with ether, which dissolves the gums and gum acids, dilute alcoholic potash ( 2.5 grams potassium hydroxide, $200 \mathrm{cc}$. water, $20 \mathrm{cc}$. alcohol) is added to the ether solution and the shaking continued. This dissolves the gum acids which together with any gums are drawn off, leaving the esters of the linseed oil acids in the ethereal layer. The resin soap solution is acidified, the acids dissolved in ether, the residue insoluble in alcohol, mentioned above, added to the solution and the whole evaporated in a small beaker on the water-bath. A small quantity of absolute alcohol is added and the evaporation repeated. This removes any water; portions of the material in the beaker are chipped out, dried over sulphuric acid and their iodine and bromine numbers determined.

From the results given by different observers it was thought 
that the Hübl iodine value could be used as a means of discrimination between a pure varnish gum and one adulterated with rosin. The iodine figures given by Schmidt and Erban ${ }^{1}$ are as follows: Rosin II.7, Angola copal, melted 42. Williams gives rosin II2, copal I30-I38. Accordingly, the iodine number was determined in the usual way using Hübl's procedure, by solution in chloroform and, except in the case of samples $A$ and $B$, the iodine was allowed to act for four hours; in these cases it acted for twentyfour.

In handling these recovered gums it is well to bear in mind that they cannot be kept much longer than one month without hardening to such an extent as to be insoluble in chloroform and carbon tetrachloride.

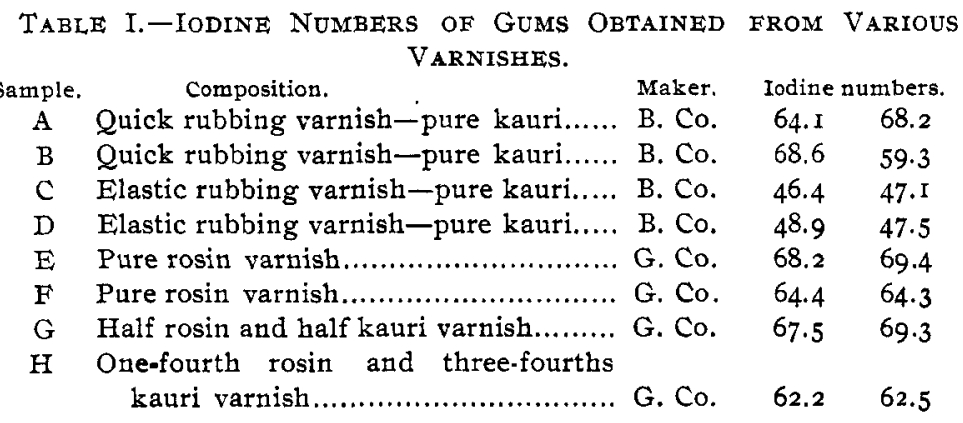

Samples $A$ and $B, C$ and $D, E$ and $F$ were the same varnishes but worked through separately.

By comparing Sample E, pure tosin, with Sample G, which is half rosin and half kauri, practically no difference is seen in the iodine numbers, hence these cannot be used as criteria by which to judge of the purity of a varnish.

The iodine value being of so little use, it was hoped that the process devised by McIlhiney would give results of more value. The method as given by him ${ }^{2}$ was applied to the gums extracted as detailed previously with the results in Table II.

The last eight results were obtained by a different operator carrying through the method at two different times.

The results do not agree remarkably well, although certain results, particularly with the pure rosin $\mathrm{E}$ and the one-fourth rosin varnishes $H$, are as close as they can be expected. The

1 Dieterich: Die Härze.

2 This Journal, 2r, ro84. 
difficulty seems to be due to the emulsification of the carbon tetrachloride with the potassium iodide, which masks the endpoint. The tendency to emulsification seems to be less with a pure rosin than with a kauri varnish.

TABLE II.-BRomine Numbers of Various Gums ObTaINED From VARNISHES.

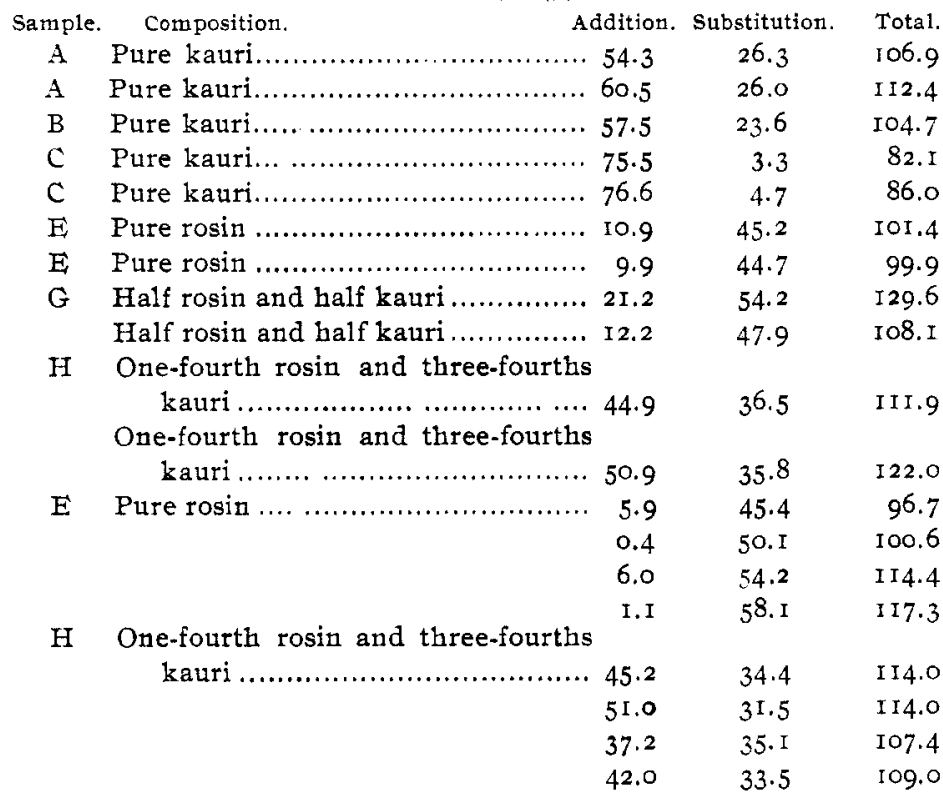

Notwithstanding this disagreement, it is easy to determine from the substitution values in the table which varnishes contain. rosin, being evidently $\mathrm{E}, \mathrm{G}$ and $\mathrm{H}$. There is so much irregularity in the numbers obtained that the method would not seem to be a satisfactory quantitative one.

The method was modified as follows: Such quantities of the resin were employed so that if $20 \mathrm{cc}$. of $\mathrm{N} / 3$ bromine solution were used, the amount of bromine left after a certain time had elapsed was very nearly equal to the amount which had acted upon the resin. The time of action of the bromine was three minutes. From 0.4 to 0.5 gram of resin was weighed into a $50 \mathrm{cc}$. graduated flask, dissolved in carbon tetrachloride and brought to the mark with the same; ro cc. of this solution were used for each determination. Window glass and black rosin were used to familiarize the operator with the method; in some cases an insoluble residue 
remained after treatment with the solvent-the clear liquid only was employed. It was found, however, that there was no difference as to whether this or the turbid liquor were used.

Table III shows a comparison of McIlhiney's original method and this modification; window glass rosin was used.

TABLE III.-BRoMINE NUMBERS OF ROSIN BY VarIoUs METHODS.

\begin{tabular}{|c|c|c|}
\hline Total. & Added. & Substituted. \\
\hline I 25.5 & 23.3 & $5^{\text {I.I }} \succ_{\text {or }}$ \\
\hline I I 9.3 & I 4.6 & 52.35 \\
\hline IO2. 8 & 24.4 & $39.2\} \mathrm{cle}$ \\
\hline 103.0 & 23.8 & $39.6\}^{\circ}$ \\
\hline 102.3 & 22.7 & d turbid solution. \\
\hline IOI. 8 & 25.5 & 38.15 \\
\hline
\end{tabular}

The method as modified was applied to resins from varnishes $B, F$ and $H$ from Table II and also to a suspected varnish $I$.

TABLE IV.-Bromine Numbers of Various Gums.

\begin{tabular}{ccrrrrrr} 
Sample. & \multicolumn{2}{c}{ Composition. } & \multicolumn{2}{c}{ Total. } & \multicolumn{2}{c}{ Bromine added. } & \multicolumn{2}{c}{ Substituted. } \\
B & Pure kauri.............. I08.7 & I07.7 & 70.1 & 73.8 & I9.3 & I 7.0 \\
F & Pure rosin.............. & 80.4 & 84.4 & 1.6 & 3.1 & 39.4 & 40.6 \\
H & I/4 R 3/4 K................ & 91.4 & 84.4 & 34.5 & 28.6 & 28.5 & 22.9 \\
I & Unknown............... & 76.4 & 76.4 & 45.3 & 41.9 & 15.5 & I 7.3
\end{tabular}

Sample $I$ is evidently not adulterated with rosin, as was shown by other tests.

The results from the Hübl and the McIlhiney processes being so unsatisfactory from a quantitative point of view, the saponification, free acid and ester values of these various gums were now obtained. These were determined in the usual way, as described in the writer's "Handbook of Oil Analysis;" the ester value is, of course, the difference between the two.

TABLE V.-Saponification, FreE Acid aNd Ester Values of GUMS FROM VARIOUS VARNISHES.

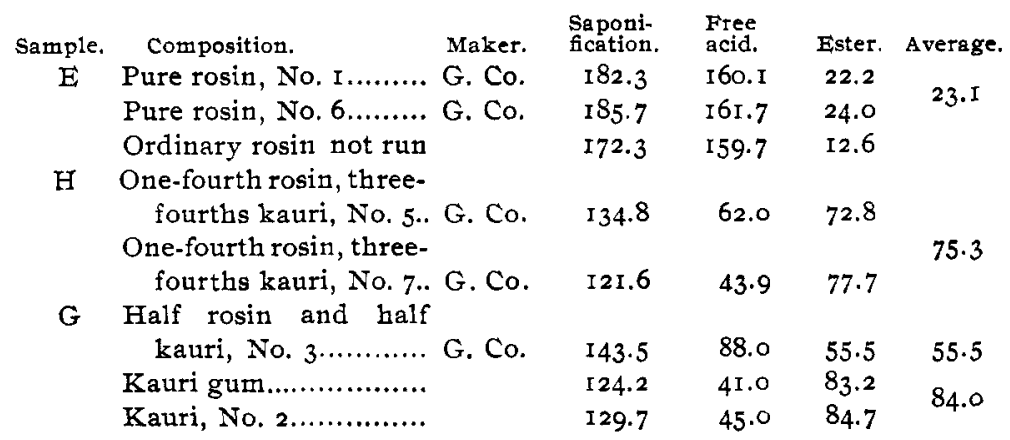


Using the average ester values obtained and the usual formula $x=\frac{100(\mathrm{I}-n)}{m-n}$ for calculating the percentage of adulteration, we find that the three-quarters kauri varnish figures 85 per cent., and the half and half kauri and rosin 53 per cent. It wotld seem that this method is fairly satisfactory but requires experimentation by other observers before implicit trust can be placed in it.

In conclusion, the writer wishes to express his indebtedness to his various assistants and students, Messrs. Hammond, Sulzer, Tufts, Merrill and Mason.

Massachusetts Institute of Technology, September, 1906.

\section{THE TECHNICAL DETERMINATION OF BENZENE IN ILLUMINATING GAS. ${ }^{1}$}

BY D. A. MORTON.

Received September $26,1906$.

THE value of benzene vapor as a light producer in illuminating gas has led to its extensive use for enriching purposes, and its exact estimation in a simple way has become a matter of consequence.

Since I per cent. only in coke oven gas gives a lighting value of more than twelve candle-power, while I per cent. of ethylene gives less than one and one-half candle-power, there is a large difference in the lighting value of these constituents and their separate determination is necessary.

Although a number of methods have been proposed for the determination of benzene and some of these requiring long and careful manipulation are quite exact, none appears to be satisfactory for use in technical work where a simple and rapid, as well as reasonably accurate, test is desired.

W. Misteli, ${ }^{2}$ in a recent review, cites the method of Haber and Oechelhaeuser $^{8}$ as being the only one suitable for testing small quantities of gas, yet even this method does not compare in rapidity and simplicity with the ordinary volumetric tests in technical analyses. The gist of the method is the absorption of the ethylene by bromine water and subsequent titration of the

1 Read at the Ithaca Meeting of the American Chemical Society.

2 J. Gasbeleucht, Sept. 9, I905, p. 804 .

3 Ber. 29, 2700. 